\title{
Sponges
}

\section{Die Rohstoffe des Tierreichs}

Herausgegeben von Ferdinand Pax und Walther Arndt. Lieferung 13. Kapitel 9: Schwämme. Von W. Arndt. Pp. 1577-2000. (Berlin : Gebrüder Borntraeger, 1937). 45 gold marks.

THIS is a new part of an encyclopædic work, 1 little known as yet in Great Britain, which deals well and thoroughly with the commercial side of natural history. There is much worth knowing about beast and bird beyond the ken of even the most learned zoologist. The trapper, the fur-trader and the plumassier, the spongemerchant and the dealer in shells, the pearl-fisher and the ivory-trader, the druggist with his fats and waxes, glues, isinglass, musk, civet, ambergris and galls, all these, not to speak of the men in Leadenhall Market or Billingsgate, are highly skilled naturalists in their own peculiar way and have a fine field of learning and observation of their own.

The volume before us, consisting of more than four hundred pages, is an extremely interesting account of the sponge fishery and the sponge market, of the many sorts of sponges known to the trade, their use and value, their place and mode of capture, and all the trade-statistics of this world-wide industry.

No man knows when sponges were first used. They were a household word in Homer's time, and Ulysses called for water and a sponge to wash down the tables and chairs after a certain sad scene in the palace. The very name is far older than Greek, and harks back to that ancient lingua franca of the Levantine fishermen to which tunny and pinna and the seine-net belong. Oppian gives a picturesque account-it might be a modern one--of the sponge-diver with a lump of lead in one hand and his crooked knife in the other, and a mouthful of oil to smooth the sea and let the sunlight through. From classical antiquity the book passes on to the trade-routes of the Middle Ages and the old Italian apothecaries' shops-and so, at last, to the sponge trade of the present day. We are shown the fine Turkeycup or Levantine sponges, the African Zimoccas, the West-Indian grass-sponges and wire-sponges, the great elephants' ears from the Philippines, and many more ; and still we are only a little way from the beginning of this interesting and useful book.

D. W. T.

\section{Complex}

\section{Lectures on Osmosis}

By Dr. F. A. H. Schreinemakers. Pp. xi +266. (The Hague: G. Naeff, 1938.) 8.50 gldrs.

DROF. SCHREINEMAKERS has been engaged since 1924 in studies in osmotic phenomena, which have hitherto only been available in Leyden dissertations and the publications of the Amsterdam Academy of Science. In this book he gives a collected account in English of his researches, which will be of great interest to those who are concerned with the transport of material in animal and regetable tissues.

The fundamental equations of osmotic equilibrium were laid down by Gibbs, and provided at one time a valuable means of investigation of the properties of solutions, which has been superseded to a great extent by more convenient methods, owing to the difficulty of preparing ideally semipermeable membranes. But ideal membranes rarely occur in Nature, and, especially in complex solutions, a baffling variety of phenomena is encountered.

\section{Osmosis}

This book is not concerned with the properties of solutions which determine the osmotic equilibrium, but with the effect of the membrane on the path by which osmotic equilibrium is approached and the different types of behaviour which may be encountered in numerous different circumstances. Thus, although osmotic flow must always proceed on the whole towards thermodynamic equilibrium, when a membrane is permeable to two or more of the substances present, it may happen that one substance is carried by another against its natural direction of osmotic flow, giving rise to apparent negative osmosis. Again, a membrane may be permeable to two substances in certain proportions ; or only within a certain range of concentration. In connexion with the latter, Prof. Schreinemakers discusses some ingenious models of mechanisms by which this may be effected (checking membranes).

Although illustrative examples are given of many of the phenomena, with membranes of pig's bladder, 'Cellophane' and parchment, the book is 